\title{
Development of Interactive Workplace Improvement Programs in Collaboration with Trade Associations of Small-Scale Industries
}

\author{
Akiyoshi ITO ${ }^{1 *}$, Kazuhiro SAKAI ${ }^{2}$ and Kazutaka KOGI ${ }^{2}$ \\ ${ }^{1}$ University of Occupational and Environmental Health, 1-1 Iseigaoka, Yahatanishi-ku, Kitakyushu, Fukuoka \\ 807-8555 Japan \\ ${ }^{2}$ The Institute for Science of Labour, Kawasaki, Japan
}

Received August 31, 2005 and accepted November 25, 2005

\begin{abstract}
Serial participatory action programs for reducing occupational safety and health risks were undertaken to know the types of support suited for small-scale industries. Working groups were formed with workplace people and occupational safety and health experts. It was agreed to develop an action-oriented strategy focusing on improving both work environment and productivity by making low-cost improvements through group work. Many workplace improvements achieved by participating enterprises and the group work procedures taken were analyzed. As supporting tools for effectively implementing the workplace improvement action programs, we developed action checklists according to industry and workplace implementation guides. Collections of local good examples also served as part of these support tools. These experiences show that keys to the sustainable action in small-scale industries are: (1) mobilization of the industry-wise network by trade associations, (2) an output-oriented strategy based on interactive group work and (3) the effective use of support tools such as low-cost action checklists and group work methods.
\end{abstract}

Key words: Workplace improvement, Action checklists, Group work, Small-scale industry, Occupational health

\section{Introduction}

Serial participatory action programs for reducing occupational health risks were undertaken to know the types of support suited for small-scale industries. We started these new projects in 1994 in collaboration with the cooperative trade associations of small and medium-sized enterprises (SMEs) in several industries. The experiences gained in the projects were examined to discuss what combinations of support activities were useful to obtain concrete results. It was agreed to develop an action-oriented strategy focusing on "improving work environment", "shortening working hours" and "retaining skilled manpower". A particular attention was paid to low-cost improvements and group work methods. Projects were conducted in seven industry-wise trade associations of SMEs during the last ten years. They

*To whom correspondence should be addressed. were the die-casting industry (1994-1999), the outdoor advertising industry (1995), the tents and sheets manufacturing industry (1996-1998), fittings carpenters (1997-1998), the glasswork industry (1997-2002), beauticians (1998-2000) and the bookbinding industry (2002-2004).

\section{Methods}

The following four steps were taken by organizing small group activities for each trade association.

In Step 1: We conducted group study for identifying major risk profiles of work environment together with questionnaire surveys.

In Step 2: We collected local good examples of risk reduction measures. This included the collection of photographs showing local good examples in the industry. Action checklists adjusted to respective industries were designed by listing practicable low-cost improvements. 
Table 1. Areas covered in an action checklist for the die-casting industry

\begin{tabular}{ll}
\hline Categories & Technical areas \\
\hline \multirow{2}{*}{ Ensuring safety } & $\begin{array}{l}\text { Improving premises (6 points) } \\
\text { Machine safety (6 points) } \\
\text { Isolation of hazardous substances (5 points) }\end{array}$ \\
\hline \multirow{3}{*}{ Reducing workload } & Materials handling (5 points) \\
& Controlling microenvironment (5 points) \\
\hline Comfstation design (5 points) \\
environment
\end{tabular}

Total: 43 checkpoints

In Step 3: We carried out comprehensive risk assessment by group work of managers and experts by means of applying action checklists.

In Step 4: We succeeded to implement workplace improvements and their evaluation. In this step, we continued group work for selecting practical measures. Self-check in small groups was also undertaken. Action-oriented guidance for their implementation was provided throughout these steps.

\section{Results}

From these experiences we identified three key points useful for facilitating the implementation of workplace improvements on the initiative of managers and workers of SMEs. The first point is that the industry-wise trade association network can facilitate maintaining safety and health, because the risk situations are common among the participating industries. The second point is that support tools such as action checklists, good examples and implementation guides are effective in confirming benefits in terms of both better safety and health and higher productivity. The third point is that an interactive group work can lead to multiple improvements in many SMEs.

Focusing on multi-area improvements was found effective. For example, main risks pointed out by the participants included heat stress, noise in the molding process, forced postures and heavy weights in handling molds in the diecasting industry. Since the identified risk profiles were common in this industry, it was appropriate and readily possible to develop the action checklist on the basis of these risk profiles.

Table 1 indicates the outline of the action checklist we developed for the die-casting industry. There are three categories corresponding to: ensuring safety, reducing workload and achieving comfortable work environment. Each category contains two or three technical areas shown
Table 2. Average number of checkpoints pointed out by managers as necessary to improve workplace conditions in 47 enterprises

\begin{tabular}{llc}
\hline Categories & Technical areas & \\
\hline \multirow{2}{*}{ Ensuring safety } & Improving premises & 3.0 \\
& Machine safety & 2.4 \\
& Isolation of hazardous substances & 1.6 \\
\hline \multirow{2}{*}{ Reducing workload } & Materials handling & 1.0 \\
& Controlling microenvironment & 2.3 \\
& Workstation design & 1.2 \\
\hline \multirow{2}{*}{ comfortable work } & Welfare facilities for refreshment & 1.7 \\
& Work organization & 2.7 \\
\hline
\end{tabular}

in Table 1, such as improving premises, machine safety and isolation of hazardous substances for ensuring safety. Five or six checkpoints were selected in each of these technical areas. In all, there are 43 checkpoints.

Table 2 shows the results of checklist application in 47 enterprises. The average number of points considered necessary to improve workplace conditions is given. The figures were higher in "improving premises", "machine safety", "controlling microenvironment" and "work organization". The total number of checkpoints amounted to as many as 16 per enterprise on average.

Figure 1 shows the examples of self-check diagrams we developed. Each diagram shows the number of checkpoints necessary to improve workplace conditions in each of eight technical areas. The circle corresponds to the average number per enterprise for the industry. And the graduation of each axis is arranged through normalization using means and standard deviations for the 47 enterprises. In Enterprise A, the self-check results plotted were almost within the circle, indicating that the workplace conditions were well-organized. However, in Enterprise B, the results were plotted mostly far above the normalized means for the industry, indicating that this small enterprise required many improvements. The improvements were necessary particularly in the areas such as premises, work stations and welfare facilities.

Table 3 shows the improvements that were implemented in the participating enterprises in the die-casting industry. Frequent improvements found in the safety category were clear passageways, storage racks and guards. About the workload and microenvironment category, pushcarts, lifters, improved hand tools and lighting were similarly frequent, but better working height, spot coolers and noise reduction were less frequent.

These less frequent improvements included those less practicable at low-cost and difficult to carry out. Nevertheless, some enterprises implemented such relatively 

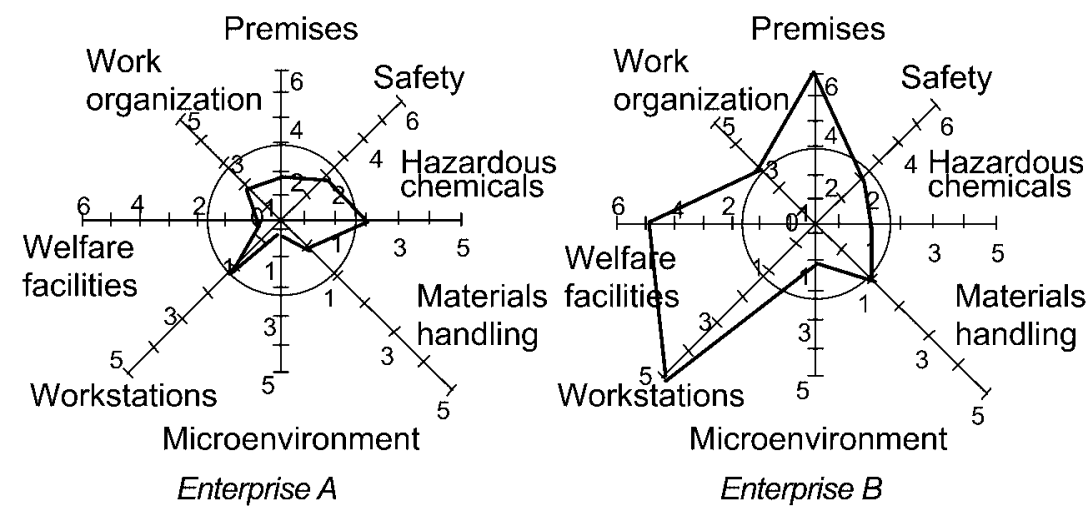

Fig. 1. Results of self-check.

Table 3. The improvements that were implemented in the participating enterprises

\begin{tabular}{lll}
\hline & $\begin{array}{l}\text { Most frequent } \\
\text { improvements }\end{array}$ & $\begin{array}{l}\text { Less frequent } \\
\text { improvements }\end{array}$ \\
\hline Safety & $\begin{array}{l}\text { Clear passageways } \\
\text { Storage racks } \\
\text { Guards }\end{array}$ & $\begin{array}{l}\text { Preventing falls } \\
\text { Safety devices } \\
\text { Isolating hazards }\end{array}$ \\
\hline \multirow{2}{*}{$\begin{array}{l}\text { Workload and } \\
\text { microenvironment }\end{array}$} & Push carts & Better work height \\
& Improved hand tools & Spot coolers \\
Nighting & \\
\hline Welfare and work & Washing facilities & Resting corner \\
organization & Work schedules & Canteens \\
& Short breaks & Buffer stocks \\
\hline
\end{tabular}

costly improvements in addition to common, low-cost improvements.

Our four steps were found effective when associated with the use of supporting tools. Throughout our serial action programs, we could confirm that the proposed four kinds of support tools are particularly effective. They are local good examples, action checklists, self-check diagrams and implementation guides.

Figure 2 clearly shows the trend toward an improved working environment in the participating enterprises of the die-casting industry. The results of questionnaire surveys conducted at three points of time are shown. Compared with the results at the starting point of our project in 1994, the results of the follow-up studies in 1996 and 1998 when were moving toward better conditions. These data were based on the self-evaluation by managers of their own workplace environment. In most of the environmental

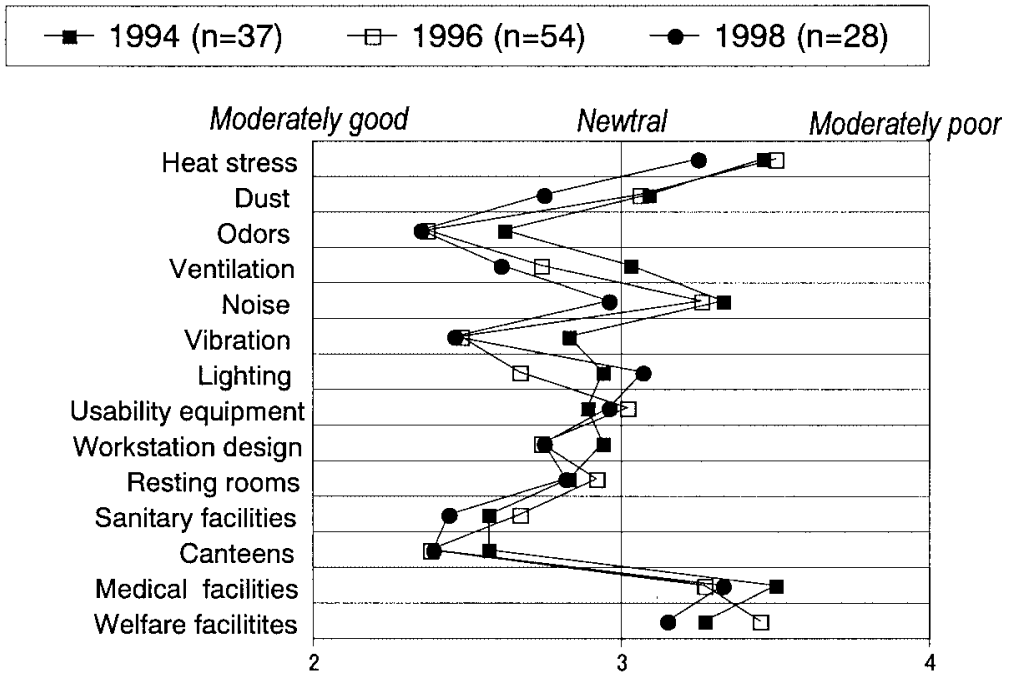

Fig. 2. Evaluation by managers about their workplace environment. 
factors, the evaluations became better in 1996 and 1998 . We could thus conclude that our activities in SMEs using the proposed strategy were successful, meeting their local needs.

\section{Conclusions}

Our experiences show that keys to sustainable action programs in SMEs are summarized in these three: (1) mobilization of the industry-wise network by trade associations of SMEs, (2) an output-oriented strategy based on interactive group work and (3) effective use of supporting tools such as checklists and group work methods.

For SMEs, interactive group work involving workplace people and experts is important because it can facilitate the effective use of the above mentioned keys and the group work process applying the proposed of supporting tools including action checklists and practical guides.

\section{References}

1) ILO (1996) Ergonomic checkpoints: Practical and easyto-implement solutions for improving safety, health and working conditions. ILO, Geneva.

2) Ito A, Kogi K, Sakai K, Watanabe A (2001) Workplace improvement needs and effective approaches in small and medium-sized enterprises: experience in the die-casting industry. J Science of Labour 77, 147-57. 